\author{
ARTIGOS
}

\title{
ZONEAMENTO DAS ÁREAS COM MAIOR PROPENSÃO PARA ADOECIMENTO PELA DENGUE NA REGIÃO INTRA-URBANA DE MONTES CLAROS (MG) A PARTIR DE VARIÁVEIS SÓCIOAMBIENTAIS E GEOESTATÍSTICA
}

Diego de Sousa Ribeiro Fonseca ${ }^{1}$

Universidade Federal de Minas Gerais

Ricardo Alexandrino Garcia ${ }^{2}$

Universidade Federal de Minas Gerais

Enviado em 14 fev. 2020 | Aceito em 23 nov. 2020

Resumo: 0 objetivo deste estudo foi determinar as áreas que têm tido maior propensão para ocorrência de infectados pela dengue na cidade Montes Claros-MG. A metodologia consistiu na aquisição de dados relativos ao número de infectados pela dengue, por bairros, nos anos 2015, 2016 e 2017; obtenção dos Índices Breteaures sobre infestação larvária pelo Aedes aegypti nos respectivos anos; uso de imagens de satélite para estimação da temperatura de superfície (TS); aquisição de dados sobre elevação do terreno e renda familiar. Posteriormente, foi realizada a organização do banco de dados; emprego da análise descritiva; aplicação da regressão linear múltipla e da interpolação. $\mathrm{O}$ uso do modelo regressivo múltiplo, StepWise progressivo, para seleção das variáveis preditoras, com maior poder para explicação dos surtos de dengue ocorridos no período, mostrou-se eficiente, permitindo que fosse operacionalizada a co-krigagem, a qual trouxe as regiões sob maior probabilidade da ocorrência de infectados pela dengue. Genericamente, a infestação larvária pelo Aedes aegypti tem acontecido na porção oeste, enquanto a infecção pela dengue tem maior propensão na porção leste da cidade, duas porções em situações econômicas distintas, onde a parte oeste concentra a população com renda mais elevada. Tal fator denota a fragilidade da população de menor renda quanto à saúde pública e a sua maior carência na atenção estratégica.

Palavras-chave: infectados; infestação larvária; temperatura de superfície; altitude; renda domiciliar.

\section{ZONNING AREAS WITH THE BIGGEST PROPENTION TO SICK PEOPLE BY DENGUE IN THE MONTES CLAROS CITY (MG) USING SOCIO ENVIRONMENTAL VARIABLES AND GEOSTATISTICS}

Abstract: The objective of this work was to delimitation the determinats areas with the most propention to occurrence of sick peoples by dengue in the Montes Claros city, Minas Gerais. The methodology was consists in the acquisition of databases relateded at infects numbers by dengue, by neighborhoods, betwen the years 2015, 2016 and 2017; obtaining of Breteau Index about larval infestation by Aedes aegypti in the related years; use of satelities imagery to estimation of land surface temperature (LST); acquisition of databases abo ut land elevation and familiar income. In the next time, was realize the organization of databases; employing the descriptive analysis; application of multiple linear regretion and interpolation of files. The use of regressive model, progressing StepWise, to selection of predictive variables, with more po explication power to disease outbreaks in the period, showed efficient, and this was permited the operationabilization of the co-kriging, which brought the regions with the more probability to dengue infectation. Overall, the larval infestation by the Aedes aegypti had happened on the west side, while the infectation by dengue have been more propention on the east side of the city, two portions in different economic situations, where the western part concentrates the population with the highest income. This factor denotes the fragility of the low-income population in terms of public health and their greater lack of strategic attention.

Keywords: infected; larval infestation; land surface temperature; elevation; familiar income.

ZONIFICACIÓN DE UBICACIONES CON MAYOR PROPENSIÓN PARA DENGUE DENTRO DE LA CIUDAD DE MONTES CLAROS (MG) A PARTIR DE VARIABLES SOCIOAMBIENTALES Y GEOSTATISTICAS

Resumen: El objetivo de este estudio fue determinar las áreas que han sido más propensas a la ocurrencia de infectados por la dengue en la ciudad Montes Claros-MG. La metodología consistió en adquirir datos sobre el número de personas infectadas por dengue, en los barrios,

1. Doutorando em Geografia pelo Instituto de Geociências IGC/UFMG). Bolsista da Fundação de Amparo à Pesquisa do Estado de Minas Gerais. Minas Gerais, Brasil. ORCID: http://orcid.org/0000-0001-5655-2646. E-mail: diegosousarf@gmail.com

2. Professor do Departamento de Geografia do Instituto de Geociências e coordenador do Laboratório de Estudos Territoriais (LESTE/IGC/UFMG). ORCID: https://orcid.org/0000-0001-7144-9866. E-mail: alexandrinogarcia@gmail.com 
en los años 2015, 2016 y 2017; obtención de los Índices de Breteaures sobre infestación larvaria por Aedes aegypti en los años respectivos; uso de imágenes de satélite para estimar la temperatura de la superficie (TS); adquisición de datos sobre elevación del terreno e ingresos familiares. Posteriormente, se organizó la base de datos; se hizo uso de análisis descriptivo; aplicación de interpolación y regresión lineal múltiple. El uso del modelo regresivo múltiple, progresivo StepWise, para seleccionar las variables predictoras, con mayor poder para explicar lo fenómeno de la dengue ocurridos en el período, resultó ser eficiente, permitiendo la operacionalización de la co-kriging, lo que llevó a las regiones bajo mayor probabilidad de personas infectadas con dengue. Generalmente, la infestación de larvas por el Aedes aegypti ha ocurrido en la parte occidental, mientras que la infección por la dengue es más probable en la parte oriental de la ciudad, dos partes en situaciones económicas diferentes, donde la parte occidental concentra la población de mayores ingresos. Este factor denota la fragilidad de la población de bajos ingresos en materia de salud pública y su mayor falta de atención estratégica.

Palabras Clave: infectado; infestación de larvas; temperatura de la superficie; altitud; ingresos del hogar

Introdução

São notados em várias cidades do Brasil, de tempos em tempos, o surgimento e o ressurgimento dos vírus de doenças transmitidas por vetores, tal como o mosquito Aedes aegypti, o qual, à medida que ocorre o crescimento urbano, a infestação larvária desse inseto parece aumentar (ALMEIDA; MEDRONHO; VALÊNCIA, 2009). Outras pragas comuns são: roedores, baratas, pombos, escorpiões, urubus e gafanhotos, todos estes quando em desequilíbrio, perturbam a qualidade do convívio citadino. Essa realidade desordenada foi prevista (MONTEIRO, 1992; SANTOS, 1998) e permanece discutida atualmente (CARLOS, 2018) devido a sua complexa solução em locais como a cidade de Montes Claros-MG, onde padrões arquitetônicos homogêneos e importados, os quais não se adequam à realidade bioclimática local (FONSECA, 2010), são mantidos e expandidos em desarmonia com o ambiente.

Ao buscar a maior salubridade nos ambientes citadinos, o estudo do comportamento espacial do mosquito Aedes aegypti (LINNAEUS, 1762) é atual e necessário, porque é este o principal transmissor de epidemias tais como a dengue, a febre amarela (JENTES et al., 2011), a febre chikungunya (CHAVES et al., 2012) e o zika vírus (CAMPOS et al., 2015).

O objetivo deste estudo foi determinar as áreas não amostradas com maior propensão para ocorrência de infectados pela dengue, período entre 2015 a 2017, através da temperatura de superfície (TS); dados de altitude, taxas de infestação larvária do transmissor da doença, o mosquito Aedes aegypti, e a renda domiciliar da população da cidade Montes Claros-MG. A partir dos resultados, o assunto poderá contribuir nessa temática a respeito da qualidade urbana e a geografia da saúde social.

\section{Material e métodos}

\section{Área de estudo}

Localizada ao Norte do Estado de Minas Gerais, porção centro-leste do município, a cidade de Montes Claros é composta atualmente por área equivalente a $92.000 \mathrm{~km}^{2}$. A altitude média é de 660 metros, especificamente na região central da cidade. As áreas com vegetação, ou não urbanizadas, 
compõem em torno de 19\% do terreno e estão situadas nas porções nordeste e sudoeste da cidade (FONSECA; BRAZ, 2010; MOREIRA; FERNANDES; NERY, 2014).

A área urbana apresenta cento e trinta e seis bairros (136), de acordo com a base cartográfica (Figura 1) fornecida pela Secretaria Municipal de Planejamento e Coordenação (SEPLAN, 2009). A população estimada para o ano de 2017 é de 402.027 pessoas; a densidade demográfica é superior a 101,41 hab/ $\mathrm{km}^{2}$. A renda média do trabalhador é de 2,2 salários mínimos, correspondente a $26 \%$ da população que se encontra ocupada; o Índice de Desenvolvimento Humano (IDH) é de 0,77 - o décimo-oitavo (18º) de Minas Gerais (IBGE, 2017).

Figura 1 - Bairros de Montes Claros e sua localização

\section{LOCALIZAÇÃO DA CIDADE MONTES CLAROS E BAIRROS}

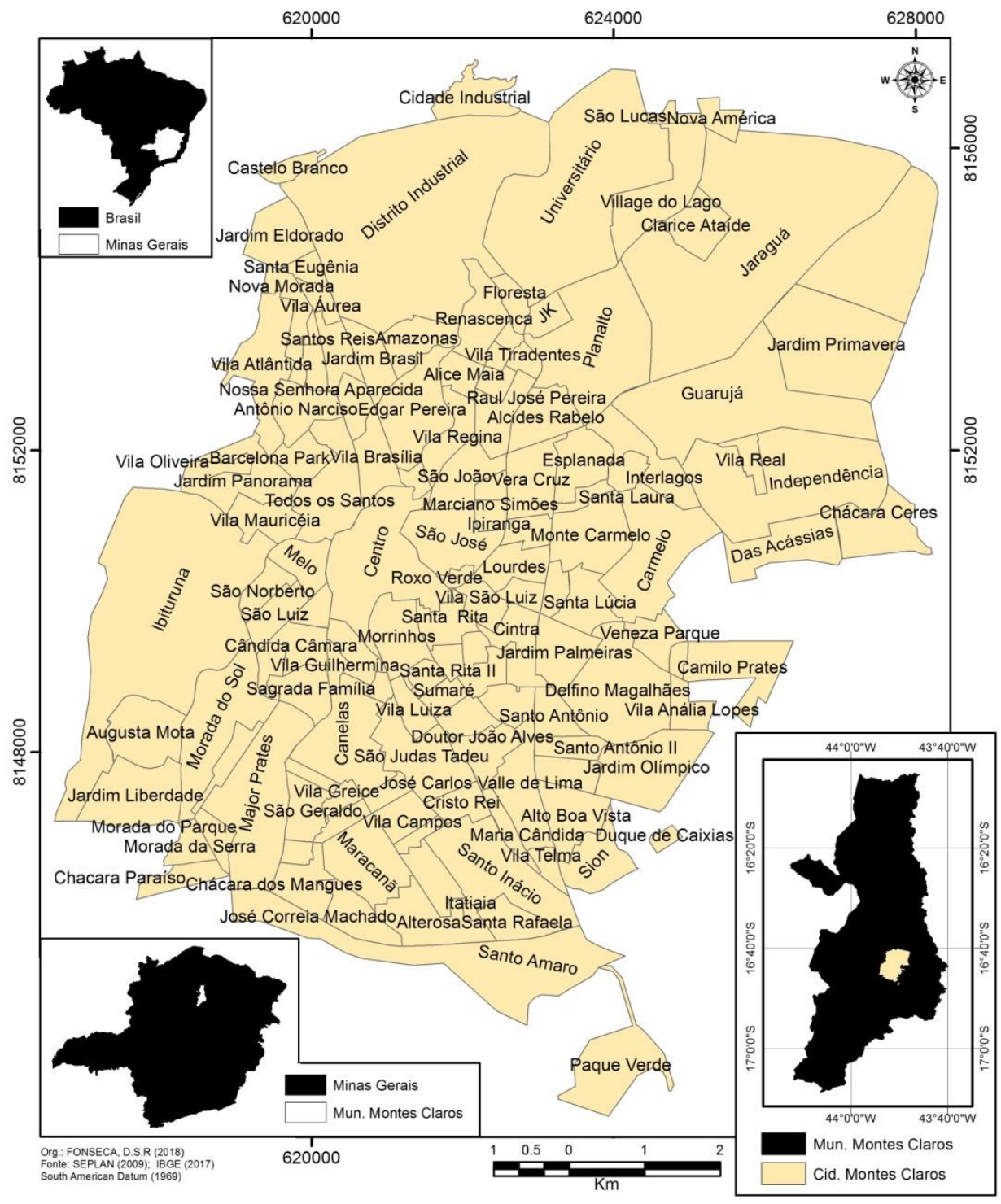

Fonte: SEPLAN (2009). Org.: do Autor, 2020 


\section{Base de dados}

Os dados a respeito do número de infectados pela dengue, por bairros, nos anos 2015, 2016 e 2017 - foram adquiridos junto à Secretaria Municipal de Saúde (SMS, 2019). Dados entomológicos foram apanhados junto ao Centro de Controle de Zoonoses (CCZ, 2017), os quais se referem ao Índice Breteau dos bairros da cidade de Montes Claros, período de 2015 a 2017, sendo os dados usados neste trabalho, conforme aquilo que foi fornecido pelo CCZ, coletados nos meses de janeiro, março e outubro. Tal índice tem sido usado como referência para os diagnósticos de infestação larvária pelo mosquito $A$. aegypti e sua mensuração é feita por meio de uma amostra probabilística dos imóveis (10\% de cada bairro) da área urbana. O delineamento amostral é feito por conglomerados, levando em consideração o quarteirão como unidade primária e o imóvel como unidade secundária (MS, 2013). O Índice Breteau leva em conta a relação entre o número de recipientes positivos e o número de imóveis pesquisados, como mostra a Equação 1:

$$
I B=\frac{\text { recipientes positivos }}{\text { imóveis pesquisados }} * 100
$$

A base cartográfica, com o perímetro dos bairros de Montes Claros, foi adquirida junto à Secretaria de Planejamento (SEPLAN, 2009) em formato vetorial Drawing database (DWG). Dados sobre a renda per capita doimicilar das áreas equivalentes aos bairros, setores sensitários, foram adquiridos junto ao Instituto Brasileiro de Geografia e Estatística (IBGE, 2010).

Imagens do satélite Landsat-8, com resolução espectral de 16 bits; freqüência de revisita igual a 10 dias; espacial de 30 metros (sensor Operational Land Image - OLI) nas bandas 4 (vermelho) e 5 (infravermelho próximo); e com resolução de 100 metros (sensor Thermal Infrared Sensor - TIRS) nas bandas 10 e 11 (infravermelho termal), foram baixadas do United States Geological Survey (USGS, 2019), órbita-ponto 218-072, as quais tiveram data de imageamento nas seguintes datas: 07/10/2017, 19/07/2017, 16/05/2017; 20/10/2016, 16/07/2016, 11/04/2016; e 02/10/2015, 28/06/2015, 25/04/2015. Tais imagens apresentam cenas que cobrem área equivalente a $180 \mathrm{~km}^{2}$. A escolha das datas teve como critério os meses de coleta de dados, realizada pelo CCZ, e a menor ocorrência de nuvens das cenas nas datas escolhidas.

\section{Procedimentos operacionais}

A primeira etapa do trabalho consistiu na organização dos dados cedidos pela SMS (2019) e pelo CCZ (2017). Os arquivos, do CCZ, originalmente em formato arquivo de texto, precisavam ser transferidos para planilha de edição de dados numéricos, a fim de torná-los editáveis digitalmente. Em seguida, devido à incompatibilidade entre a base cartográfica adquirida junto à SEPLAN (2009), com 136 bairros, e os dados do Centro de Controle de Zoonoses, com 186 divisões da cidade em bairros, esta última foi padronizada conforme a primeira base.

A base cartográfica em formato DWG foi convertida para o formato shapefile, por meio do aplicativo computacional ArcGIS, versão 10.2, e cada perímetro dos bairros foi alterado para polígono, a fim de transformar o arquivo em um banco de dados que pudesse ser passível de inserção dos atributos (Índice Breteau, total de infectados por dengue, renda e temperatura por bairros) em sua respectiva tabela. 
Para se obter a temperatura de superfície (TS), foram manipuladas as cenas do satélite Landsat-8 nas bandas 11 e 10 (termal) e 5 e 4 (infravermelho próximo e vermelho) por meio do raster calculator (ArcGIS), conforme orientação do serviço geológico dos Estados Unidos (USGS, 2018), quando, inicialmente, converteu-se o valor do número digital para valores de radiância, com uso dos metadados baixados com as imagens, tal como mostra a Equação 2:

$$
L \lambda=M L Q c a l+A L
$$

Onde:

$L \lambda=$ Radiância espectral do topo da atmosfera (Watts $\left./\left(m^{2 *} \operatorname{srad} * \mu m\right)\right)$;

$M L$ = banda específica, multiplicada pelo fator de reescalonamento, contido nos metadados (RADIANCE_MULT_BAND_x, onde $x$ é o número correspondente à banda);

$A L=$ banda específica, adicionada com o fator de reescalonamento contido nos metadados RADIANCE_ADD_BAND_X, onde $x$ é o número correspondente à banda);

Qcal = valores calibrados relativos ao pixel (DN) do produto padrão.

Em seguida, fez-se a conversão para temperatura de topo da atmosfera (Kelvin), a qual é obtida por meio da Equação 3:

$$
T=\frac{K_{2}}{\operatorname{In} \frac{K_{1}}{L \lambda+1}}
$$

Onde:

$T=$ Temperatura do topo da atmosfera $(\mathrm{K})$;

$L \lambda=$ radiância espectral (Watts $\left./\left(m^{2} * \operatorname{srad}^{*} \mu m\right)\right)$;

K1 = banda termal específica pela constante, a partir dos metadados (K1_CONSTANT_BAND_X, onde $x$ é o valor da respectiva banda);

K2 = banda termal específica pela constante, a partir dos metadados (K2_CONSTANT_BAND_X, onde x é o valor da respectiva banda).

E, posteriormente, foi gerada a temperatura da superfície terrestre (TS), em graus Celsius, por meio da aplicação da Equação 4:

$$
\frac{T S}{1+w *\left(\frac{T S}{p}\right) * \ln (e)}
$$

Onde:

TS = Temperatura a partir do satélite; 


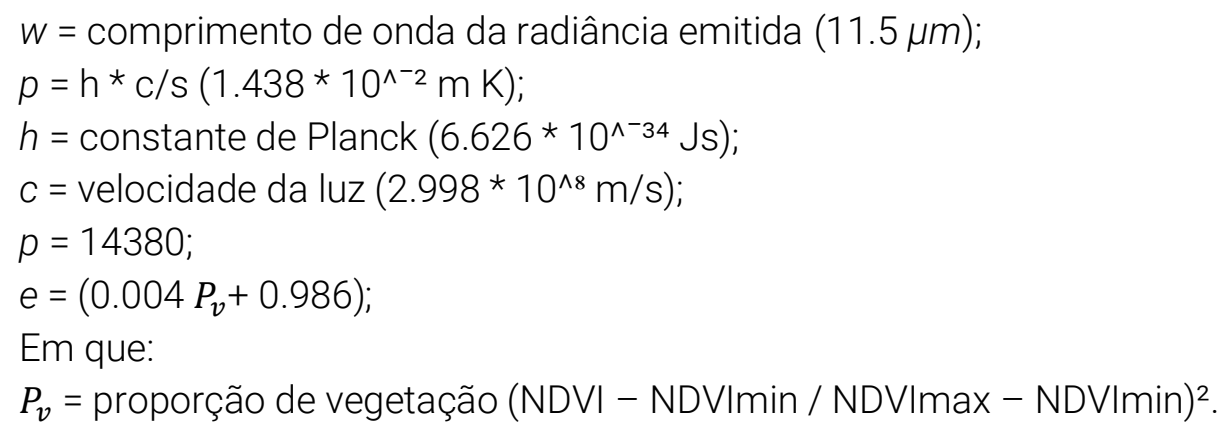

As operações retro-explicadas para obtenção da TS foram feitas com as bandas 10 e 11 do satélite Landsat-8, em seguida, após a obtenção da temperatura a partir de cada uma delas, foi realizado o cálculo da média (por pixel) entre essas bandas e, posteriormente, entre as imagens, por meio do Cell Statistics, ferramenta do ArcGIS. A imagem gerada (média das três datas dos anos 2015, 2016 e 2017) foi recortada, a fim de se obter as temperaturas médias e os desvios-padrões respectivos aos determinados bairros da cidade de Montes Claros.

É necessário salientar que as temperaturas de superfície estimadas condizem com o horário do imageamento das cenas, os quais ocorreram aproximadamente às $10 \mathrm{~h}$ e $30 \mathrm{~min}$. Essas temperaturas estimadas, na latitude $-16^{\circ} .68^{\prime} \mathrm{S}$; longitude: $-43^{\circ} .83^{\prime} \mathrm{W}$ - foram certificadas com os dados de temperatura da série histórica da estação: 83437 de Montes Claros-MG (INMET, 2018), condizendo com os respectivos dias, e em horário próximo à geração das imagens do Landsat-8.

Os dados sobre altitude e declividade foram manipulados a partir do Modelo Digital de Elevação (MDE) Topodata adquirido, pelo qual se gerou curvas de nível com equidistância de 20 metros, e sucessivamente criaram-se Redes Triangulares Irregulares (TIN). Manipulando esse arquivo foi obtida a altitude média sobre cada bairro, método similar ao descrito em Silva; Rodrigues (2009); Peluzio et al (2010).

Tendo disponível a base cartográfica da SEPLAN (2009) convertida para shapefile e com os atributos inseridos, houve sucessivamente a exportação e posterior importação da tabela para o software Bioestat, versão 5.0 (AYRES, 2007), pelo qual se realizou análises estatísticas com todos os bairros, tais como: a análise descritiva, teste de hipóteses e a regressão pelo método StepWise progressivo (AYRES, 2007; ALMEIDA; MEDRONHO; VALÊNCIA, 2009; MARTINS, 2010). Este modelo de regressão linear múltipla (StepWise) foi produtivo para seleção automática das variáveis preditivas com maior peso $\left(\mathrm{R}^{2}\right)$, por meio da sua significância estatística (CUNHA-CRUZ; NADANOVSKY, 2003). A partir da escolha das variáveis com maior poder explicativo, no ArcGIS, versão 10, na ferramenta Geostatistical Analyst, Geostatistical Wizard - efetuou-se o método interpolativo da co-krigagem - para estimar as áreas sob efeito do agravo do número de infectados por dengue na cidade de Montes Claros nos anos analisados (LANDIM, 2006), por meio da relação entre a distância dos pontos analisados e seu ajuste com as variáveis preditivas descritas (UTSUMI; GALO; TACHIBANA, 2015). 0 resultado dos mapas gerados foi sintetizado a partir da aplicação da média simples das áreas entre eles, utilizando-se o recurso - Raster Calculator.

\section{Resultados e discussão}

Os dados referentes ao número de adoecidos por dengue e seus agravos apresentou as seguintes médias para os respectivos anos 2017, 2016 e 2015: 1,11, 20,2 e 12,6 - sendo estas consideradas diferentes $(p<0.01)$ a partir do teste de hipóteses empregado. Quanto ao Índice 
Breteau, referente a infestação larvária pelo mosquito A. aegypti nos bairros da cidade Montes Claros, apresentaram as correspondentes médias: 5,4, 4,5 e 4,3\% - sendo o ano 2017 e o 2015, significativamente diferentes $(p<0,05)$ conforme teste de médias, e a relação entre os demais consideradas iguais. Os valores apresentaram elevada variabilidade, aqueles com maior dispersão para o número total de pessoas adoecidas foram relativos a 2017 (coeficiente de variação igual a 170, 4\%) e 2015 (153\%); ao mesmo tempo, a maior dispersão verificada quanto ao Índice Breteau, também ocorreu nesses dois anos, porém, em ordem inversa: 2015 (coeficiente de variação igual a 98,4\%) e 2017 (68,6\%). Por conta disso, os valores mínimos dos dados mativeram-se em zero (0) nos anos, enquanto os valores máximos apresentaram diferenças, tal como pode ser verificado na Tabela 1 a seguir.

Tabela 1 - Estatística descritiva dos dados referentes ao número de adoecidos por dengue e os Índices Breteaures (mosquito Aedes aegypti) dos anos 2017, 2016 e 2015, na cidade Montes Claros-MG

\begin{tabular}{ccccccc}
\hline Ano & \multicolumn{2}{c}{2017} & \multicolumn{2}{c}{2016} & \multicolumn{2}{c}{2015} \\
\hline Variável & I.B & $\begin{array}{c}\mathbf{N}^{\circ} \\
\text { Adoec. }\end{array}$ & I.B & $\begin{array}{c}\mathbf{N}^{\circ} \\
\text { Adoec. }\end{array}$ & I.B & $\begin{array}{c}\mathbf{N}^{\circ} \\
\text { Adoec. }\end{array}$ \\
\hline Amostra & 136 & 136 & 136 & 136 & 136 & 136 \\
\hline $\begin{array}{c}\text { Valor } \\
\text { mínimo }\end{array}$ & 0 & 0 & 0 & 0 & 0 & 0 \\
\hline $\begin{array}{c}\text { Valor } \\
\text { máximo }\end{array}$ & 18,5 & 11 & 15,5 & 125 & 29,5 & 144 \\
\hline Mediana & 4,9 & 0 & 4,2 & 12 & 3,3 & 5 \\
\hline $\mathbf{1}^{\text {o quartil }}$ & 3 & 0 & 2,7 & 4 & 1,7 & 2 \\
\hline $\mathbf{3}^{\text {o quartil }}$ & 7,1 & 1 & 6 & 28 & 6,4 & 14,25 \\
\hline Média & 5,4 & 1,11 & 4,5 & 20,2 & 4,3 & 12,6 \\
\hline $\begin{array}{c}\text { Desvio- } \\
\text { padrão }\end{array}$ & 3,7 & 1,89 & 2,9 & 23,75 & 4,2 & 19,23 \\
\hline $\begin{array}{c}\text { Coef. } \\
\text { Var. (\%) }\end{array}$ & 68,6 & 170,4 & 65,1 & 117,6 & 98,4 & 153 \\
\hline \multicolumn{2}{c}{ Fonte: dados do CCZ (2017); SMS (2019). Org.: do Autor, 2020. } \\
\hline
\end{tabular}

A elevada dispersão nos dados referentes ao ano 2015 pode ser notada ao ser observado o Figura 2, na qual a representação espacial do Índice Breteau encontra-se acima de 12,8\% em pontos distintos da cidade, bairros: Sion, região leste, e São Luiz, região central. Outros locais com valores superiores a 7,1\% estão dispostos heterogeneamente entre as regiões da cidade, tais como: Village do Lago, região norte; Vila Anália Lopes, região leste; e o Melo, posicionado na região central. Para melhor interpretação, tal como informa o Ministério da Saúde (MS, 2013) relativo às taxas referentes ao Índice Breteau, quando estas encontram-se acima de 5\% devem ser consideradas altas, ou fora da faixa de equilíbrio. No entanto, conforme esclarece Gomes (1998), a estratificação do Índice Breteau em níveis de risco deve ser analisado com critério, sendo razoável o estudo e análise particularizada ao caso específico de cada lugar, em escalas detalhadas. 
Figura 2 - Distribuição espacial do Índice Breteau do Aedes aegypti (\%) nos bairros da cidade Montes Claros, no ano 2015

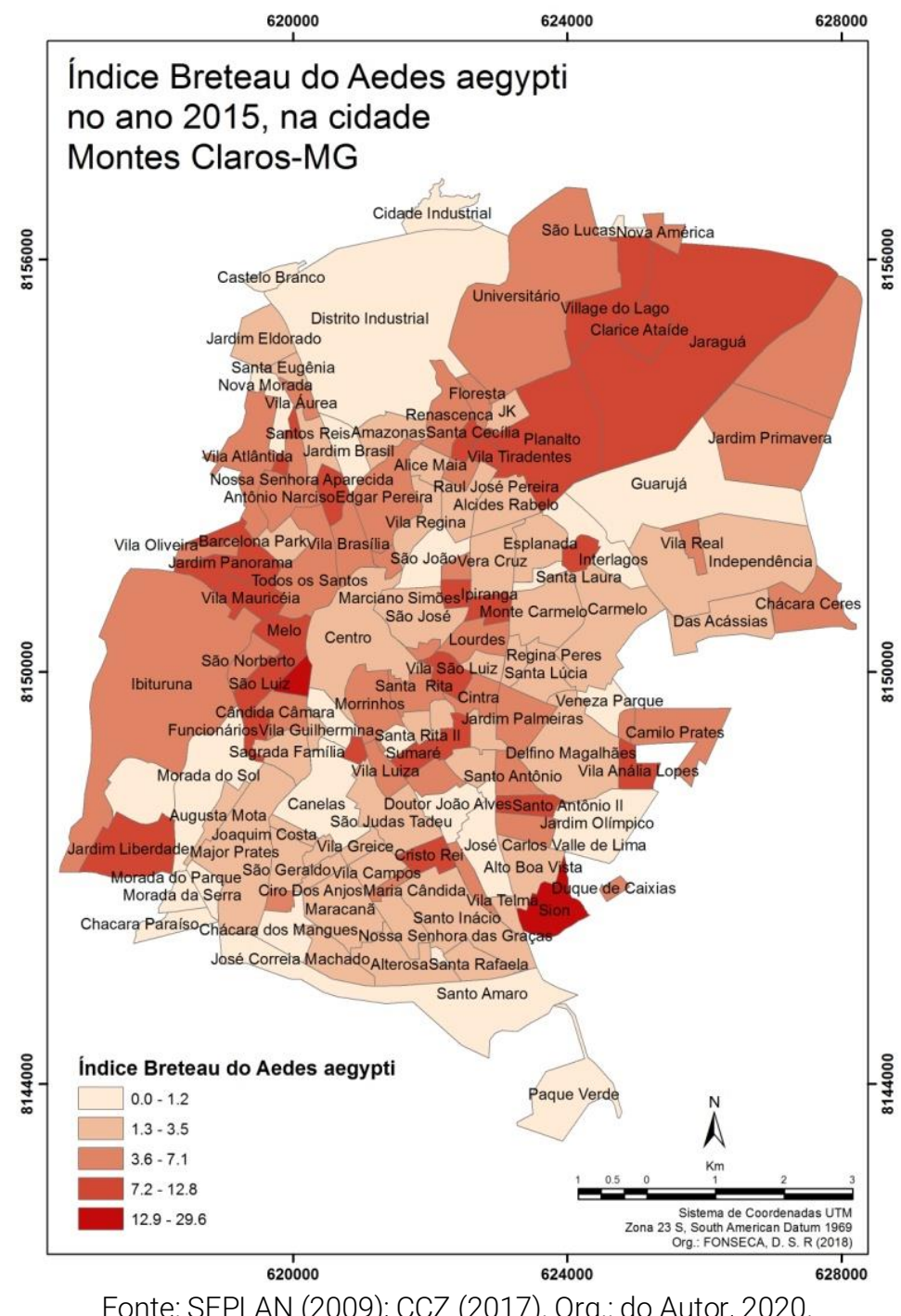

Fonte: SEPLAN (2009); CCZ (2017). Org.: do Autor, 2020.

O ano 2016 apresentou valores acima de 9,1\% em locais como: Nova América, região norte; Monte Carmelo, região leste; e o bairro Nossa Senhora das Graças, região sul. Valores acima de 6,1\% são vistos, por exemplo, no bairro Village do Lago; Vila Anália Lopes; e no Ibituruna, região oeste. Diferentemente do ano 2015, o ano 2016 teve maior quantidade de bairros agrupados na classe em tons de vermelho intenso, os quais foram aqueles de maior infestação larvária, tal como pode ser observado no Figura 3. 
Figura 3 - Distribuição espacial do Índice Breteau do Aedes aegypti (\%) nos bairros da cidade Montes Claros, no ano 2016

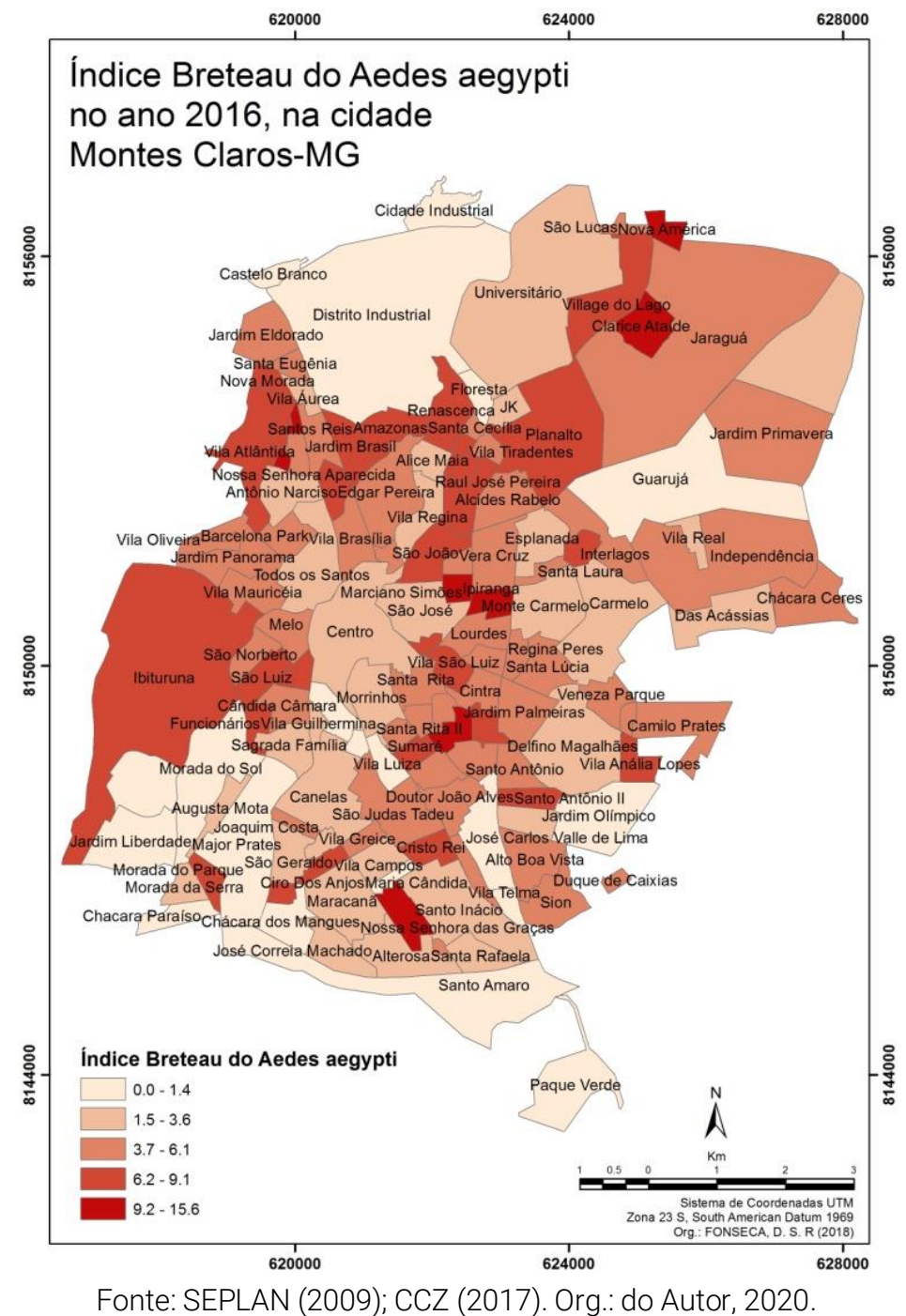

Em 2017 foram notadas áreas com valores superiores a 11,7\% do índice de infestação larvária em bairros como: Clarice Ataíde, região norte; Santa Rita II e Sumaré, na região leste da cidade. Áreas com o índice superior a 7,1\% estiveram nos seguintes locais: Floresta, região norte; Independência, região leste; Sion e no Ibituruna. Ao interpretar de forma abrangente as informações cartográficas presentes nos mapas representativos dos três anos em análise, é verificada a tendência a maior aglomeração dos valores elevados do Índice Breteau na porção centro-oeste da cidade, analise a Figura 4 a seguir. Essa região difere das demmais porque é nela onde se concentra a populaão com renda mais alta do perímetro urbano montesclarense. Na cidade em estudo, há a predominância da 
alta densidade construtiva associada à renda baixa da população, a qual ocupa cerca de $70 \%$ desse território (LEITE; BRITO, 2011).

Figura 4 - Distribuição espacial do Índice Breteau do Aedes aegypti (\%) nos bairros da cidade Montes Claros, no ano 2017

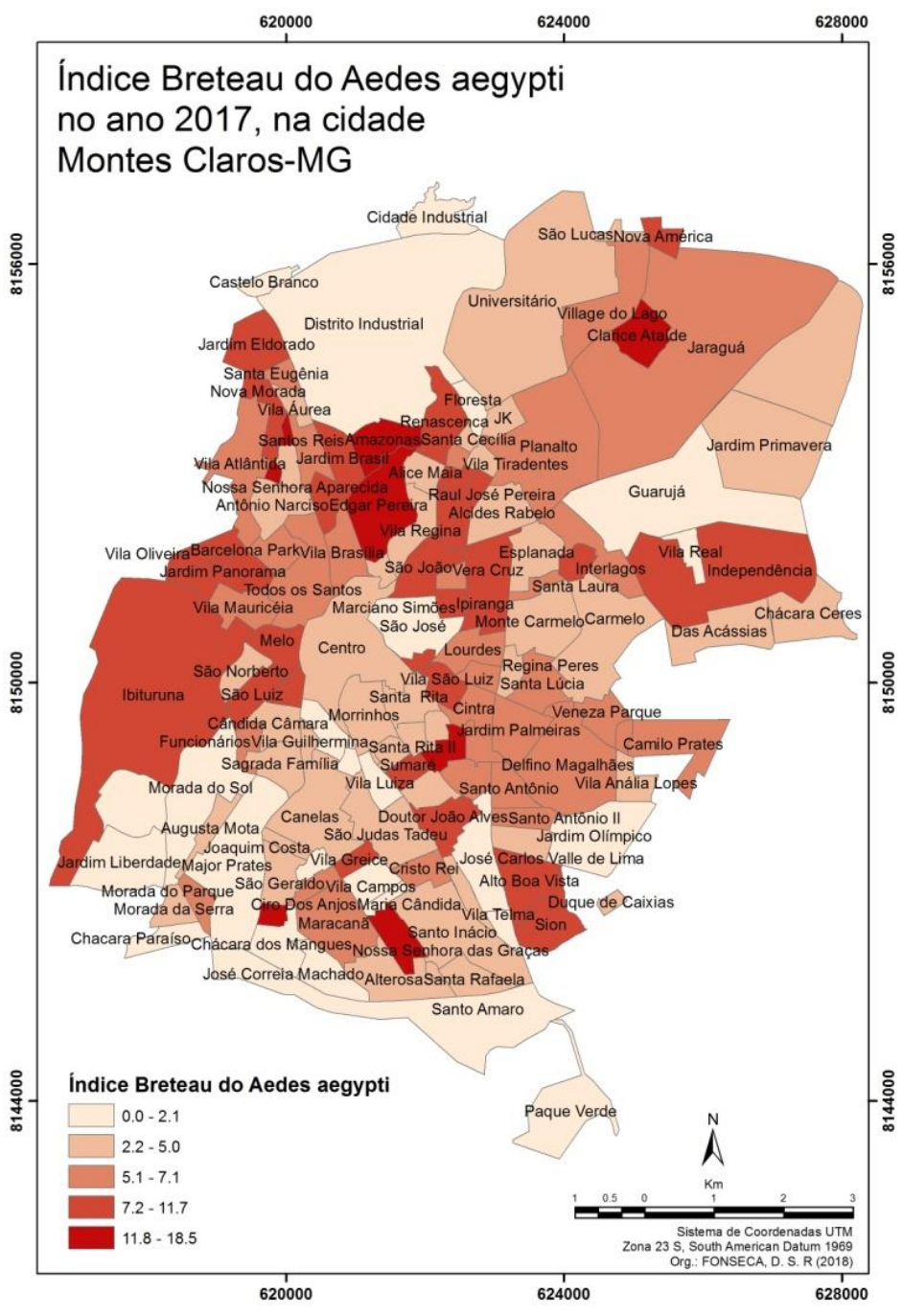

Fonte: SEPLAN (2009); CCZ (2017). Org.: do Autor, 2020.

Ao aspirar relacionar o Índice Breteau do A. aegypti com a variável temperatura, foram manipuladas as imagens do satélite Landsat-8, as quais permitiram estimar as médias de superfície da cidade Montes Claros-MG em três datas de cada ano trabalhado. Dessa forma, obtiveram-se as áreas da cidade com médias amenas e aqueles locais com picos de temperatura elevadas (Figura 5). A temperatura mínima da cidade ficou em $17,6^{\circ} \mathrm{C}$, a máxima em $29,1^{\circ} \mathrm{C}$, a média obtida foi de $24^{\circ} \mathrm{C}$, com o desvio-padrão de $1,15^{\circ} \mathrm{C}$. Pode ser interpretado que as regiões com temperaturas amenas, em 
tons de azul, estão posicionadas, pontualmente em espaços do sudoeste, norte e noroeste da cidade Montes Claros.

Figura 5 - Média das temperaturas de superfície e as zonas críticas com maior ocorrência larvária do mosquito Aedes aegypti ao longo dos anos 2017, 2016 e 2015

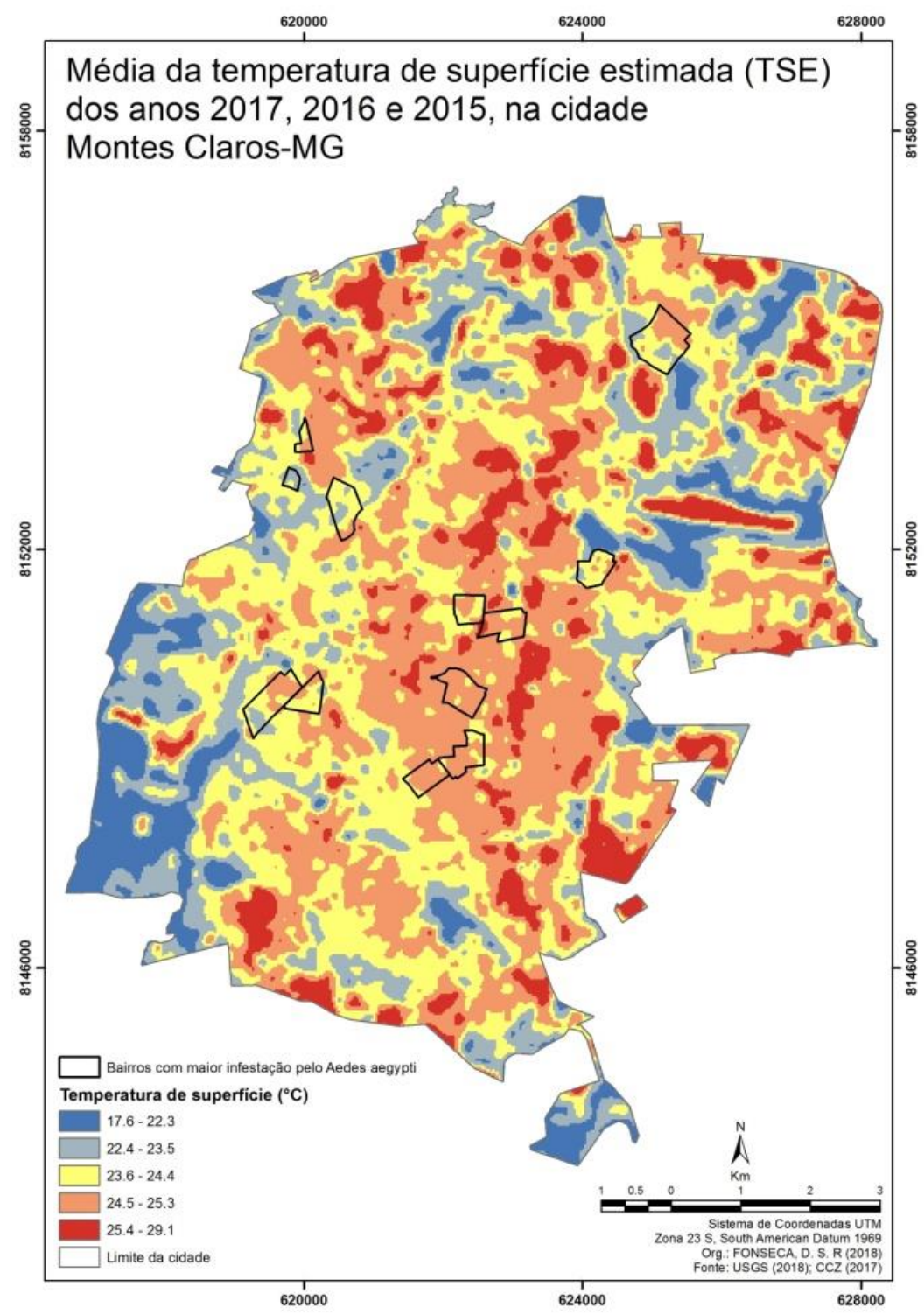

Fonte: SEPLAN (2009); CCZ (2017); USGS (2019). Org.: do Autor, 2020

Por meio desta mesma imagem, Figura 5, puderam ser observados os bairros críticos para maior ocorrência larvária do mosquito $A$. aegypti ao longo dos três anos em estudo, onde foram selecionados os $25 \%$ dos locais com valores de infestação mais elevados, correspondentes ao terceiro quartil dos respectivos anos (reveja Tabela 1). 0 resultado desse método apresentou 28 bairros em 2015; 34 para 2016; e 34 para o ano 2017. Os locais onde houve repetições em mais de um (1) ano para maior ocorrência dos focos positivos do mosquito Aedes, encontram-se representados nos polígonos pretos da Figura 5. Por meio desses polígonos é visualizado os bairros: Bela Paisagem e Bela Vista, na região oeste; Clarice Ataíde, Ipiranga, região leste; Jardim Santa Maria, 
região central; Marciano Simões, região leste; Nossa Sa Aparecida, região norte; Santa Laura, região leste; Santa Rita II, São Luiz, região central; Sumaré e a Vila São Luiz, região leste. Ao tomar como exemplo esses bairros, conforme interpretação visual prévia dos polígonos e as isotermas do mapa, são notadas faixas de calor diversificadas, o que aparentemente, indica não existir qualquer relação entre temperatura e infestação larvária pelo mosquito $A$. aegypti nas áreas mais problemáticas dos três anos em análise.

Cientes da multiplicidade dos fatores abrangidos na maior ocorrência dos agravos epidemiológicos envolvendo a dengue e seu vetor, e com a intenção de estabelecer conexões entre informações sobre elevação do terreno e incidência larvária do mosquito A. aegypti, é compreendido que a cidade Montes Claros apresenta altitude média de 660 metros, sobretudo na região central da cidade. As áreas de maior elevação (900m) estão situadas na direção Sul (sudeste) e as de menor $(600 \mathrm{~m})$ localizam-se ao Norte (noroeste). O terreno, em geral, é pouco abrupto (declividade média em torno de $2,35^{\circ}$ ), áreas com maior desnível estão posicionadas à Oeste e Sul da área urbana (INPE, 2018), tal como pode ser interpretado por meio da Figura 6. Essa análise se torna necessária porque as diferenças na elevação do relevo montesclarence poderiam interferir no comportamento da infestação relativa ao inseto em estudo, e talvez, no maior número de doentes por dengue, tendo em vista por exemplo, a velocidade de escoamento das águas, sua distribuição e acumulação ao longo do perímetro urbano, levando à melhor acomodação desse inseto transmissor de enfermidades.

Figura 6 - Intervalos de classes altimétricas representando a morfologia do relevo da cidade Montes Claros-MG

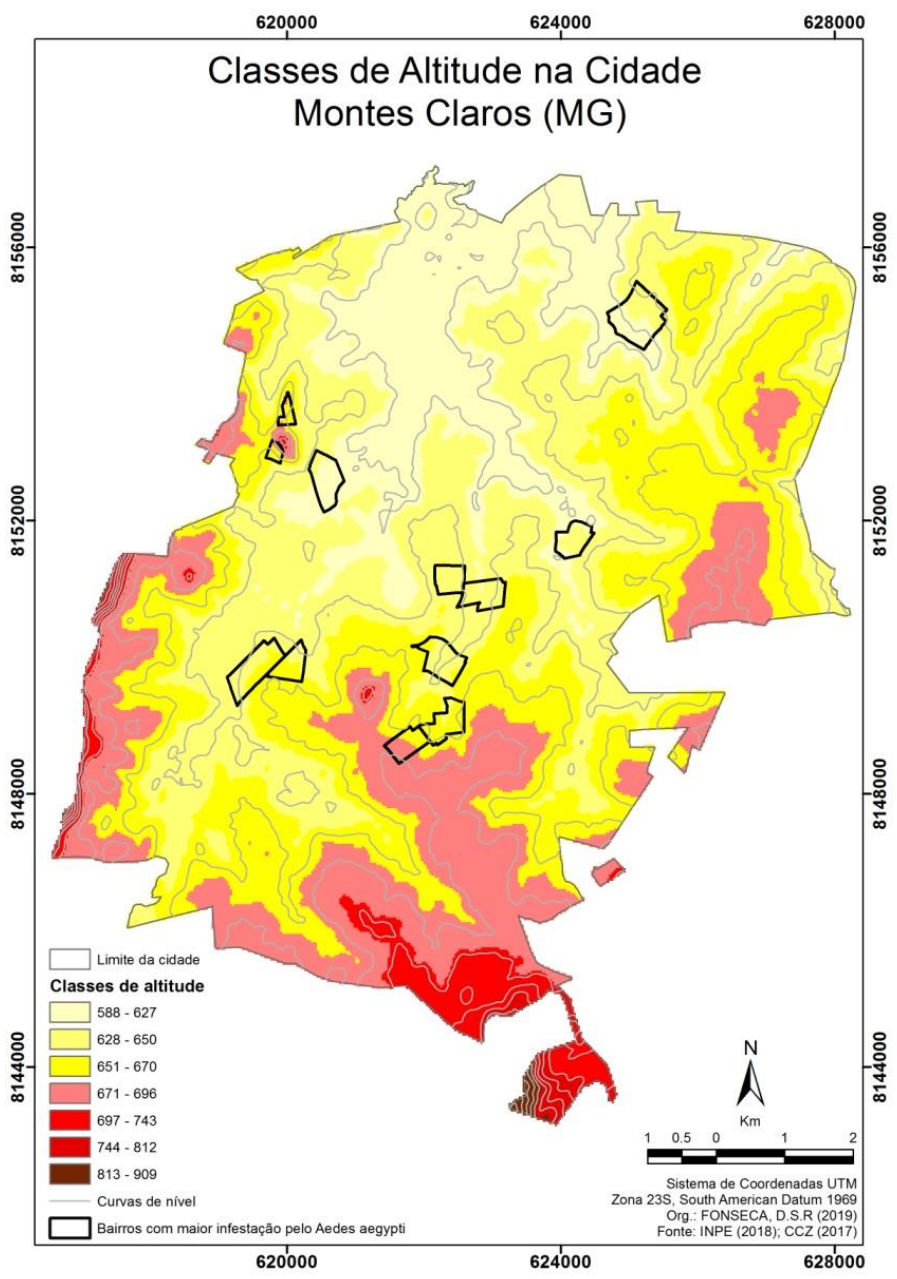

Fonte: SEPLAN (2009); INPE (2018). Org.: do autor, 2020 
Conforme a interpretação produzida por meio da observação da imagem anterior, Figura 6, nos bairros mais críticos para infestação larvária pelo principal mosquito transmissor da dengue, polígonos pretos em destaque, aparentemente, eles não estiveram relacionados com a altimetria do terreno da cidade em foco. Esse aspecto evidencia a dificuldade para se compreender as relações entre os múltiplos fatores desencadeadores das doenças transmitidas pelo mosquito Aedes.

Através da interpretação da Figura 7, nota-se na cidade em estudo a predominância da renda baixa da população. As rendas mais altas encontram-se em torno dos bairros, por exemplo: Ibituruna e Todos os Santos (região oeste), em tom escuro de cinza. Aqueles com renda mais baixa são, por exemplo, os bairros: Castelo Branco (região norte) e Santo Amaro (região sul), em tom amarelado. As áreas intermediárias, em diferentes intensidades do verde, onde a população tem vivido com renda domiciliar média entre 358 e 815 reais, conforme o Censo de 2010, predominam em toda a área urbana.

Figura 7 - Classes de renda domiciliar, por bairros, na cidade Montes Claros-MG

Renda domiciliar média, por bairros, na cidade

Montes Claros-MG conforme Censo 2010

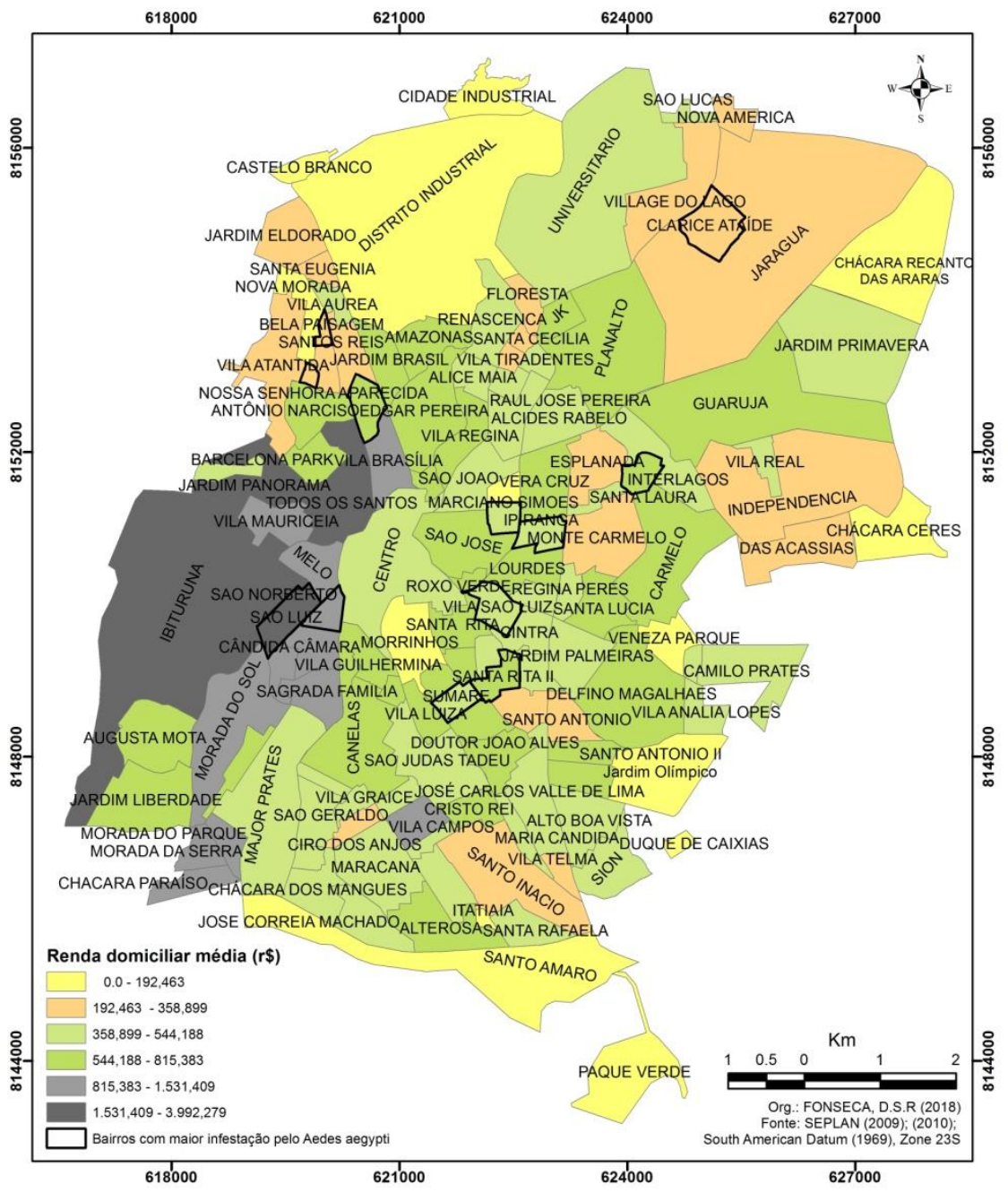

Fonte: SEPLAN (2009); IBGE (2010). Org.: do Autor, 2020. 
Ao focar a atenção nos bairros que têm havido maior infestação larvária no período analisado, poligonais com perímetros mais escuros inseridas nas classes de renda do mapa, vistos na Figura 7, são notados extratos financeiros diversificados contidos neles, o que aparentemente, indica não existir qualquer relação entre renda e infestação larvária pelo mosquito $A$. aegypti nessas áreas mais problemáticas dos três anos em análise.

A partir das perspectivas já levantadas ao longo deste estudo, e, procurando compreender mais incisivamente os fatores corelacionados à maior proliferação da dengue - e sua relação com a infestação larvária pelo A. aegypti - analisando fatores ambientais e socioambientais -, realizou-se a regressão multifatorial por meio do método StepWise progressivo. A principal finalidade foi estabelecer, com os parâmetros utilizados na construção deste trabalho, as variáveis com maior poder explicativo para o aumento do número de infectados pela dengue entre os anos 2015, 2016 e 2017. Conforme é mostrado na Tabela 2 a seguir, o número de adoecidos pela dengue no ano de 2015 ( $R^{2}$ inicial $=53,9 \%$ ) é o dado que mais influencia na predição do somatório dos adoecidos ocorridos em 2016; em seguida, a altitude, com acréscimo de 0,84\% no valor do R²; em terceiro lugar o Índice Breteau (I.B) de 2015, com acréscimo de 0,51\% no valor do R²; seguido da temperatura de superfície (TS), a qual acrescentou 0,49\% ao poder explicativo da variável dependente; e por último, a renda domiciliar foi responsável por um incremento de 0,01\% no coeficiente de determinação múltipla ajustado final $\left(R^{2}=56,1 \%\right)$. Apesar de algumas dessas variáveis terem contribuído pouco para o aumento do poder preditivo, todas elas foram estatisticamente significativas $(p<0,01)$. A resposta tardia do Índice Breteau e sua influência futura nos processos de saúde-adoecimento são esperados, e tal assunto já foi discutido por diversos autores (TEIXEIRA; CRUZ, 2011; BOWMAN et al., 2014).

Tabela 2 - Modelo de regressão multifatorial (StepWise progressivo) para aferição das variáveis preditivas com maior poder explicativo para estimar a variável dependente (número de adoecidos por dengue em 2016)

\begin{tabular}{|c|c|c|c|c|c|c|c|c|c|c|c|}
\hline \multicolumn{5}{|c|}{ Var. Dependente (Y): Adoec. 2016} & $\mathbf{R}$ & \multirow{2}{*}{$\begin{array}{c}\mathbf{R}^{\mathbf{2}} \\
53,970\end{array}$} & \multirow{2}{*}{$\begin{array}{c}\begin{array}{c}\text { Variação } \\
\mathbf{R}^{\mathbf{2}}\end{array} \\
53,970 \%\end{array}$} & \multirow{2}{*}{$\begin{array}{c}\mathbf{G L} \\
1,134\end{array}$} & \multirow{2}{*}{$\frac{\mathbf{F}}{157,089}$} & \multirow{2}{*}{$\begin{array}{c}\begin{array}{c}\text { p- } \\
\text { valor }\end{array} \\
0,000\end{array}$} & \multirow{2}{*}{$\begin{array}{c}\begin{array}{c}\text { QM } \\
\text { Erro }\end{array} \\
261,780\end{array}$} \\
\hline & & & & $\begin{array}{c}\text { Adoec. } \\
2015\end{array}$ & 0,734 & & & & & & \\
\hline & & & Altitude & $\begin{array}{c}\text { Adoec. } \\
2015\end{array}$ & 0,740 & 54,810 & $0,840 \%$ & 2,133 & 80,659 & 0,000 & 258,908 \\
\hline & & $\begin{array}{c}\text { I.B } \\
2015\end{array}$ & Altitude & $\begin{array}{c}\text { Adoec. } \\
2015\end{array}$ & 0,743 & 55,320 & $0,510 \%$ & 3,132 & 54,470 & 0,000 & 257,950 \\
\hline & TS & $\begin{array}{c}\text { I.B } \\
2015\end{array}$ & Altitude & $\begin{array}{l}\text { Adoec. } \\
2015\end{array}$ & 0,747 & 55,810 & $0,490 \%$ & 4,131 & 41,358 & 0,000 & 257,061 \\
\hline $\begin{array}{l}\text { Renda } \\
\text { dom. }\end{array}$ & TS & $\begin{array}{c}\text { I.B } \\
2015\end{array}$ & Altitude & $\begin{array}{c}\text { Adoec. } \\
2015\end{array}$ & 0,749 & 56,150 & $0,010 \%$ & 5,130 & 32,842 & 0,000 & 259,003 \\
\hline
\end{tabular}

O conjunto das variáveis para predição dos adoecidos no ano 2017 têm ligeira diferença quanto à ordem dos parâmetros com maior peso para explicação da variável dependente $(Y)$, apesar de todos aqueles que serão mostrados na Tabela 3 , a seguir, serem significativos $(p<0,01)$. Para explicação da quantidade de pessoas doentes vista em 2017, 32,49\% do peso da predição se dá com o número de adoecidos ocorrido no ano anterior, 2016, conforme os dados utilizados; a altitude incrementa o $\mathrm{R}^{2}$ em 1,60\%; seguida da renda domiciliar, a qual acrescenta $0,66 \%$ ao poder preditivo do modelo; a temperatura de superfície responde por 0,41\%; e o Índice Breteau de 2016 aumenta em 0,20\% o coeficiente de determinação múltipla ajustado, o qual teve desempenho final igual a 35,36\%. 
Tabela 3 - Modelo de regressão multifatorial (StepWise progressivo) para aferição das variáveis preditivas com maior poder explicativo para estimar a variável dependente (número de adoecidos por dengue em 2017)

\begin{tabular}{|c|c|c|c|c|c|c|c|c|c|c|c|}
\hline \multicolumn{5}{|c|}{ Var. Dependente (Y): Adoec. 2017} & \multirow{2}{*}{$\frac{\mathbf{R}}{0,570}$} & \multirow{2}{*}{$\begin{array}{l}\begin{array}{l}\mathbf{R}^{2} \\
(\boldsymbol{\%})\end{array} \\
32,49\end{array}$} & \multirow{2}{*}{$\begin{array}{l}\text { Variaç. } \\
\mathbf{R}^{2}(\%) \\
32,5\end{array}$} & \multirow{2}{*}{$\frac{\mathbf{G L}}{1,134}$} & \multirow{2}{*}{$\frac{\mathbf{F}}{64,5}$} & \multirow{2}{*}{$\begin{array}{c}\begin{array}{c}\text { p- } \\
\text { valor }\end{array} \\
0,000\end{array}$} & \multirow{2}{*}{$\begin{array}{c}\mathbf{Q M} \\
\text { Erro } \\
2,435\end{array}$} \\
\hline & & & & $\begin{array}{c}\text { Adoec. } \\
2016\end{array}$ & & & & & & & \\
\hline & & & TS & $\begin{array}{c}\text { Adoec. } \\
2016\end{array}$ & 0,573 & 32,89 & 0,41 & 2,133 & 32,6 & 0,000 & 2,438 \\
\hline & & $\begin{array}{c}\text { I.B } \\
2016\end{array}$ & TS & $\begin{array}{c}\text { Adoec. } \\
2016\end{array}$ & 0,575 & 33,09 & 0,2 & 3,132 & 21,8 & 0,000 & 2,450 \\
\hline & Altit. & $\begin{array}{c}\text { I.B } \\
2016\end{array}$ & TS & $\begin{array}{c}\text { Adoec. } \\
2016\end{array}$ & 0,589 & 34,70 & 1,6 & 4,131 & 17,4 & 0,000 & 2,409 \\
\hline $\begin{array}{l}\text { Renda } \\
\text { dom. }\end{array}$ & Altit. & $\begin{array}{c}\text { I.B } \\
2016\end{array}$ & $\mathrm{TS}$ & $\begin{array}{c}\text { Adoec. } \\
2016\end{array}$ & 0,594 & 35,36 & 0,7 & 5,130 & 14,2 & 0,000 & 2,403 \\
\hline
\end{tabular}

Fonte: dados do IBGE (2010); CCZ (2017); INPE (2018); USGS (2018); SMS (2019).

Org.: do Autor, 2020

Ao ser testada a correlação direta entre a ocorrência do vetor Aedes e o número de adoecidos ocorridos nos respectivos anos, por localidade, o teste não apresentou resultados significativos ( $p$ > 0,05). No entanto, vários estudos mostram que nem sempre há qualquer associação entre as taxas do $A$. aegypti e o número de infectados pelas enfermidades propagadas por tal mosquito (TEIXEIRA; CRUZ, 2011; BOWMAN et al., 2014; RIZZI et al., 2017).

Dispondo dos resultados mostrados nas Tabelas 2 e 3 , os quais demonstram hierarquicamente as variáveis que contribuíram mais para a predição do número de pessoas adoecidas nos anos 2016 e 2017 por bairro. E ainda, a partir de um arquivo de pontos referentes aos centróidos representativos desses bairros de Montes Claros (MG) - no qual fez-se a inserção dos dados em sua tabela de atributos - efetuou-se a co-krigagem como método interpolativo para espacialização dessas áreas objetivando o ajuste do resultado por meio da corrrelação entre as três variáveis mais explicativas para as dependentes (UTSUMI; GALO; TACHIBANA, 2015). Para o ano de 2016, esse ajuste foi feito através das variáveis: número de adoecidos pela dengue no ano de 2015, a altitude e o Índice Breteau (I.B) de 2015. Para o ano de 2017, o ajuste foi feito por meio das variáveis: número de adoecidos ocorrido em 2016, altitude e a renda domiciliar. A interpolação foi produtiva na estimação das áreas não amostradas, tendo em vista que os Postos de Saúde da Família (PSFs), presentes nos bairros da cidade, forneceram as informações quantitativas, por meio da Secretaria Municipal de Saúde (SMS, 2019), de modo pontual. Dessa forma, conforme o balisamento espacial dos vizinhos desses pontos, essa estatística espacial para estimação das áreas prováveis para ocorrência dos adoecidos tornarase assertiva no presente estudo.

A partir da interpretação da Figura 8, a seguir, é percebido que o comportamento espacial das áreas com maior número de afetados pela dengue nos anos 2016 e 2017 variou, sobretudo porque o ano de 2016 apresentou maior número de infectados pela doença. Locais com número elevado de enfermos, comuns aos dois anos, podem ser notados entorno dos bairros: Delfino Magalhães e Santo Antônio (região leste), e ainda, ao redor do Major Prates (região sudoeste). No entanto, por meio das duas imagens representativas desses anos, fica difícil o estabelecimento preciso das regiões mais problemáticas, com o maior número de prováveis adoecidos e daqueles que poderão adoecer nos anos em sequência. 

2017 na cidade Montes Claros-MG

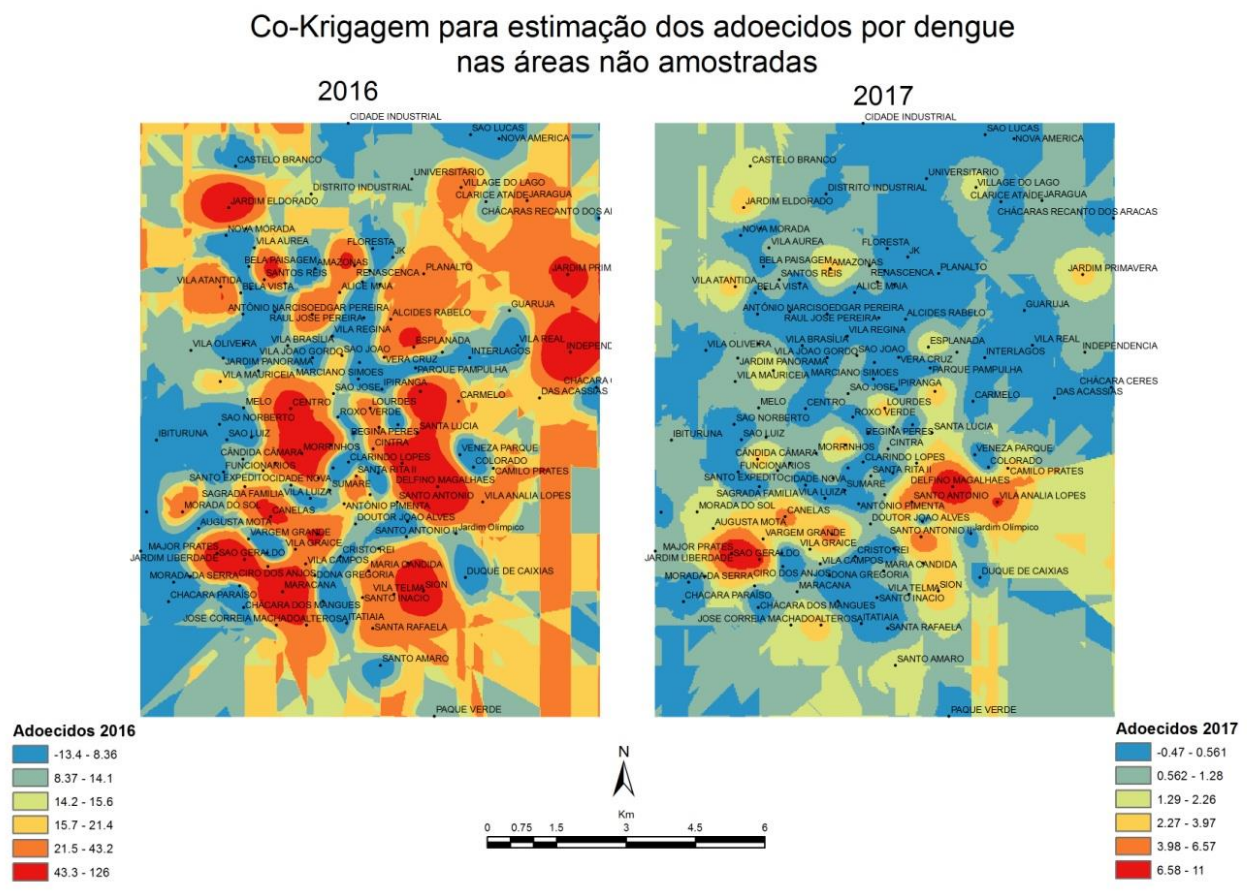

Fonte: dados do IBGE (2010); CCZ (2017); INPE (2018); USGS (2018); SMS (2019). Org.: do Autor, 2020.

Na busca pela maior facilidade para interpretação dos dados interpolados, foi calculada a média dos valores entre as imagens referentes aos anos 2016 e 2017, visto na Figura 8, o que resultou na Figura 9, a qual mostra, quase homogeneamente, que o maior número de adoentados tem ocorrido espacilmente mais, em toda a porção leste da cidade, mais frequentemente próximo aos bairros Santa Lúcia e Santo Antônio; e na parte sul - em torno do Ciro dos Anjos e Maracanã (em vermelho intenso). Esta prerrogativa demonstra a dicotomia existente entre a área com maior incidência do mosquito Aedes aegypti, predominante na porção centro-oeste - onde estão os mais ricos, com aqueles de menor renda média, os quais são os que mais sofrem com a dengue, mesmo quando o vetor não encontra-se diretamente em seus locais de residência.

Esse comportamento pode estar relacionado à melhor qualidade de vida daqueles com maior poder aquisitivo, o que inclui: alimentação mais saudável, maior prática de exercícios e melhor assistência médica - fatores que talvez influam diretamente no menor risco de contrair a doença. Os locais mais amenos quanto ao quantitativo de adoecidos, em tom de azul celeste, Figura 9 a seguir, têm ocorrido, por exemplo, nas adjacências dos bairros: Ibituruna, Antônio Narciso, Vila Regina e Universitário (este na região norte da cidade). Os valores variam entre 3,64 a 21,7, segmentados por classes coropléticas. 
Figura 9 - Média dos valores da interpolação das áreas mais prováveis, não amostradas, para os adoecidos por dengue nos anos 2016 e 2017 na cidade Montes Claros-MG

\section{Mapa sintético da co-krigagem para estimação das áreas propensas ao adoecimento por dengue nos locais não amostrados da cidade Montes Claros-MG}

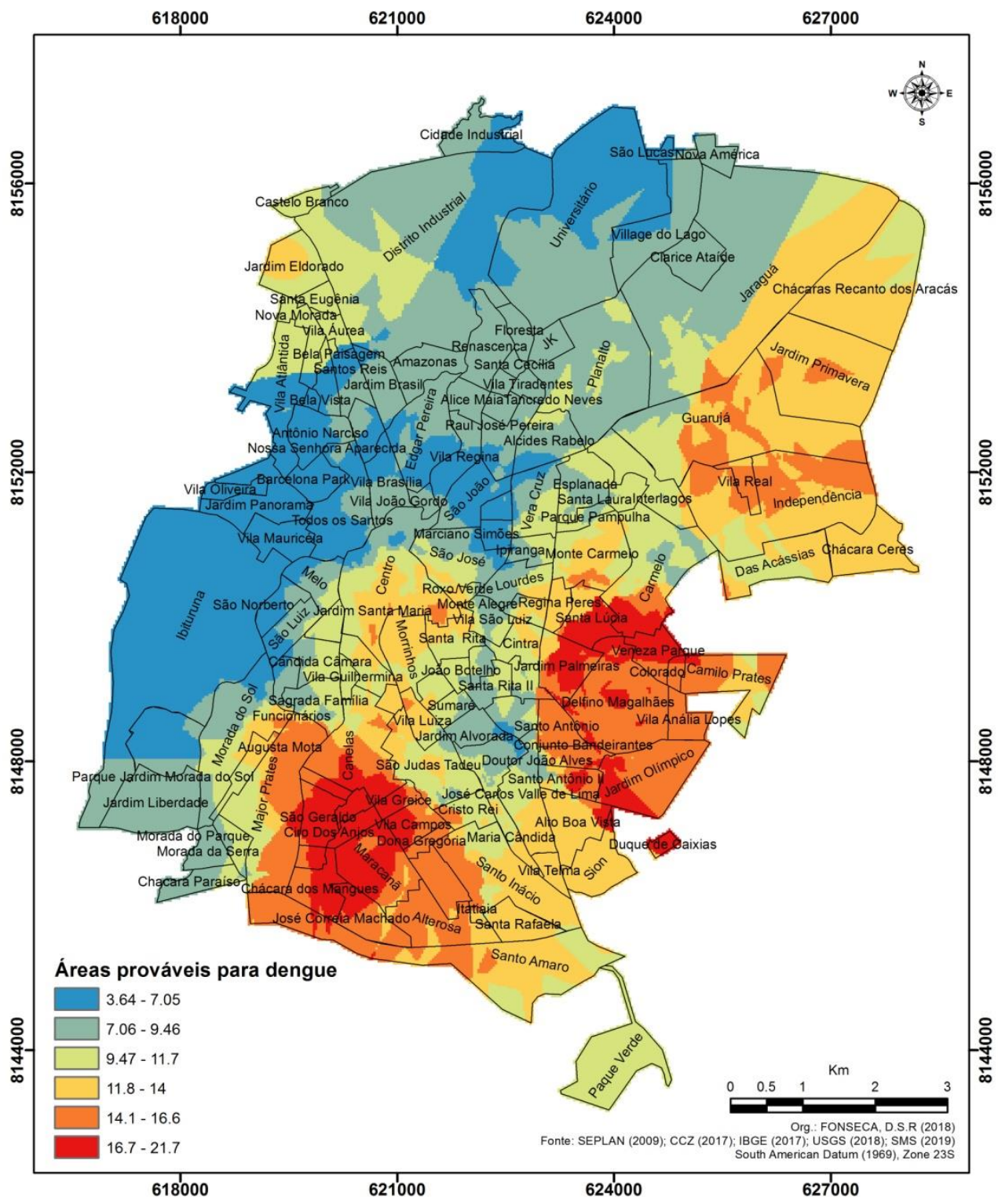

Fonte: dados do IBGE (2010); CCZ (2017); INPE (2018); USGS (2018); SMS (2019). Org.: do Autor, 2020

Conforme trabalho realizado em Curitiba-PR, Lunardon (2017) mostra haver uma relação multifatorial entre o maior número de infectados por dengue, infestação larvária pelo A. aegypti e os campos de calor da cidade. Outro aspecto para agravar a intensificação da ocorrência dos depósitos positivos do inseto é a precariedade do saneamento básico citadino, quando há acúmulo de resíduos sólidos em áreas não controladas (ALMEIDA; SIVLA, 2018). A má gestão da infra-estrutura urbana é 
preocupante no sentido de, atualmente, inexistir uma vacina eficaz a todos os sorotipos circulantes transmitidos pelo Aedes aegypti, tornando a melhor opção o controle dessa praga, a qual está respaldada numa ação combinada de fatores, envolvendo o ser humano, o vírus da dengue, o vetor e o ambiente (JENTES et al., 2011; RIZZI et al., 2017).

Certos trabalhos apontam variáveis termopluviométricas como as que mais corroboram para intensificação larvária do inseto transmissor da dengue (LANA et al., 2018), o qual é pouco resistente a temperaturas inferiores a $5^{\circ} \mathrm{C}$, mas muito propício às regiões com médias anuais em torno dos $28^{\circ} \mathrm{C}$, tal como o sítio urbano examinado neste estudo, sobretudo na primavera-verão, época com pluviosidade e temperaturas altas (AJUZ; VESTENA, 2014; CAMPOS et al., 2015; SILVA et al., 2015). Ao tomar como parâmetro as premissas apontadas, torna-se imprescindível buscar melhorar a qualidade urbana, com a diminuição dos ambientes insalubres, tais como os depósitos de entulho e lugares altamente impermeabilizados, onde podem estar as "ilhas de calor" (MONTEIRO; MENDONÇA, 2003).

Quanto aos materiais adquiridos para realização deste estudo, apesar de muito utilizado em pesquisas entomológicas, o Índice Breteau para avaliação do nível de infestação larvária, deve ser usado com ponderação devido ao seu caráter amostral para geração dos dados, os quais têm direta relação com as épocas das auditorias no campo pesquisado e a pluviosidade ocorrente no período (BOWMAN et al., 2014). Essa relação entre chuva e maior propagação larvária do mosquito Aedes não está estritamente condicionada ao maior número de adoecidos por região geográfica (TEIXEIRA; CRUZ, 2011). Na verdade, ainda existe certa carência de estudos relacionados à quantificação dos mosquitos e o grau de transmissividade das doenças por ele propagadas. O mais recomendado é a não generalização dos parâmetros, os quais devem estar adequados às peculiaridades locais, nas escalas mais detalhadas dos ambientes. Mesmo assim, nesse sentido, o planejamento territorial da cidade, por meio do plano diretor, deve levar em consideração a manutenção dos espaços, promovendo a drenagem mais eficiente, maior preservação da vegetação natural principalmente nas áreas baixas do terreno, e, quando possível, construir e preservar os espelhos d'água citadinos, para promoção do maior equilíbrio térmico dos lugares. Tal como ficou evidente, a população carente é aquela que mais sofre com os agravos em saúde, portanto, o planejamento estratégico dos espaços deve se ater a essa maior vulnerabilidade das pessoas com menor renda.

\section{Considerações finais}

O uso do modelo multifatorial StepWise progressivo, para seleção das variáveis preditivas com maior peso explicativo para explicação dos surtos de dengue ocorridos em 2016 e 2017, mostrou-se eficiente, permitindo que fosse operacionalizada a co-krigagem, a qual trouxe as áreas sob maior probabilidade da ocorrência de infectados pela dengue em Montes Claros-MG.

A experiência na operacionalização deste trabalho, tendo como objetivo principal a estimação das áreas sob maior propensão para ocorrência de infectados pela dengue nos bairros da cidade, através das variáveis preditivas de ajuste trabalhadas, indicou que as análises sobre a infestação da dengue, e larvária pelo A. aegypti, devem ser realizadas através de multifatores. Isso possibilita ampliar a compreensão e combate dessa epidemia em estudo, conforme as especificidades locais, nas maiores escalas de detalhe, tal como a usada neste estudo.

A incorporação de um amplo sistema geográfico de banco de dados (SGBD) e a manutenção de profissionais capacitados para trabalhar, unindo dados de saúde (epidemiológicos) e a espacialização destes, conforme sua significância estatística, certamente traria evoluções acachapantes no controle e mitigação das ameaças à saúde social. Essa prerrogativa seria eficiente, 
caso o resultado das análises fossem usados para a tomada de decisões mais acertadas e menos voltada à promoção política e dos interesses financeiros exclusivamente.

\section{Agradecimentos}

O primeiro autor agradece à Fundação de Amparo à Pesquisa de Minas Gerais (FAPEMIG) pelo apoio e financiamento desta pesquisa, por meio da concessão da bolsa de doutorado. Gratidão prolongada ao Programa de Pós-Graduação em Geografia, do Instituto de Geociências (IGC), da Universidade Federal de Minas Gerais (UFMG). 


\section{Referências}

AJUZ, L.C.; VESTENA, L. (2014). Influência da pluviosidade e temperatura ambiente na longevidade e fecundidade dos Aedes aegypti e Albopictus na cidade de Guarapuava-PR e possibilidade de superinfestação. Revista Hygeia, Uberlândia, v. 10, n. 18, p. 1-18.

ALMEIDA, A.S; MEDRONHO, R.A.; VALÊNCIA, L.I.O. (2009). Análise espacial da dengue e o contexto socioeconômico no município do Rio de Janeiro, RJ. Revista de Saúde Pública, São Paulo, v. 43, n. 4, p. 666-673.

ALMEIDA, C, A. P.; SILVA, R. M. (2018). Análise da ocorrência dos casos de dengue e sua relação com as condições socioambientais em espaços urbanos: os casos de João Pessoa, Cabedelo e Bayeux, no Estado da Paraíba - Brasil. Hygeia, Uberlândia, v. 14, n. 27, p. 56-79.

AYRES, M. (2007). BioEstat. Versão 5.0. Belém: Soc. Civ. Mamirauá, MCT - CNPq.

BOWMAN, L.R; RUNGE-RANZINGER, S.; MCCALL, P. J. (2014). Assessing the relationship between vector indices and dengue transmission: a systematic review of the evidence. PLOS Neglected Tropical Diseases, San Francisco, v. 8, n. 5, p. 1-11.

BRAZ, C. K. R.; FONSECA, D. S. R.; AMARAL, V.B.; MIRANDA, W. A. (2013). Teste da correlação entre hipsometria e índices de ocorrência do mosquito Aedes aegypti na cidade de Montes Claros-MG com dados dos anos 2009 e 2010. Caminhos de Geografia, Uberlândia, v. 14, n. 47, p. 199-207.

CAMPOS, G. S; BANDEIRA, A. C.; SARDI, S. I. (2015). Zika virus outbreak, Bahia, Brazil. Emerging Infectious Diseases, Atlanta, v. 21 n. 10, p. 1885-1886.

CARLOS, A. F. A (org.). (2018). Crise urbana. São Paulo: Contexto.

CCZ, CENTRO DE CONTROLE DE ZOONOZES. (2017). Guia prático do LIRAa (2015-2017). Relatório técnico, Prefeitura Municipal de Montes Claros. Montes Claros: Divisão de epidemiologia.

CHAVES, T. S. S; PELLINI, A. C. G; MASCHERETTI, M; JAHNEL, M. T; RIBEIRO, A. F; RODRIGUES, S. G; VASCONCELOS, P. F. C.; BOULOS, M. (2012). Travelers as sentinels for Chikungunya Fever, Brazil. Emerging Infectious Diseases, Atlanta, v. 18, n. 3, p. 529-530.

CUNHA-CRUZ, J; NADANOVSKY, P. (2003). Doenças periodontais causam doenças cardiovasculares? Análise das evidências epidemiológicas. Caderno de Saúde Pública, Rio de Janeiro, v. 19, n. 2, p. 357368.

FONSECA, D.S.R. (2010). Análise bioclimática do bairro Morada do Parque de Montes Claros (MG). Caminhos de Geografia, Uberlândia, v. 11, n. 33, p. 138 - 156.

FONSECA, D.S.R; BRAZ, C.K.R. (2010). Investigação epidemiológica da distribuição geográfica do Aedes aegypti na cidade de Montes Claros (MG) com uso de geotecnologias. Revista Brasileira de Cartografia, Rio de Janeiro, v. 62, n. 03, p. 489-503.

GOMES, A. C. (1998). Medidas dos níveis de infestação urbana para aedes (stegomyia) aegypti e aedes (stegomyia) albopictus em programa de vigilância entomológica. Informe Epidemiológico SUS, Brasília-DF, v.7, n.3, p. 49-57.

IBGE, INSTITUTO BRASILEIRO DE GEOGRAFIA E ESTATÍSTICA. Cidades (2017). Disponível em: $<$ https://cidades.ibge.gov.br/brasil/mg/montes-claros/panorama>. Acesso em: 05 de dezembro de 2017.

IBGE, INSTITUTO BRASILEIRO DE GEOGRAFIA E ESTATÍSTICA. Senso Demográfico 2010, universo por setores sensitários (2010). Disponível em: <https://www.ibge.gov.br/estatisticas/downloadsestatisticas.html>. Acesso em: 05 de dezembro de 2018.

INMET, INSTITUTO NACIONAL DE METEOROLOGIA. BDMEP - Banco de Dados Meteorológicos para Ensino e Pesquisa. Disponível em: <http://www.inmet.gov.br/portal/index.php?r=bdmep/bdmeps. Acesso em: 06 de maio de 2018. 
INPE, INSTITUTO NACIONAL DE PESQUISAS ESPACIAIS. Modelo TOPODATA (2008). Disponível em: <http://www.webmapit.com.br/inpe/topodata/>. Acesso em: 07 de março de 2018.

JENTES, E. S.; POUMEROL, G.; GERSHMAN, M. D.; HILL, D. R.; LEMARCHAND, J.; LEWIS, R. F.; STAPLES, J. E.; TOMORI, O.; SMITH, A. W.; MONATH, T. P. (2011). The revised global yellow fever risk map and recommendations for vaccination, 2010: consensus of the Informal WHO Working Group on Geographic Risk for Yellow Fever. The Lancet, London, v. 11, p. 622-632.

LANA, R.M; MORAIS, M. M; LIMA, T. F. M; CARNEIRO, T. G. S; STOLERMAN, L. M; SANTOS, J. P. C; CORTÊS, J. C; EIRAS, A. E.; CODEÇO, C. T. (2018). Assessment of a trap based Aedes aegypti surveillance program using mathematical modeling. PLoS ONE, San Francisco, v. 13, n. 1, p. 1-16. LANDIM, P.M.B. (2006). Sobre Geoestatística e mapas. Terra e Didatica, Campinas, v.2, n.1, p.19-33. LUNARDON, K. A. F. (2017). Aplicação da análise multicritério para espacialização de condicionantes de focos de Aedes aegypti em Curitiba/PR. Hygeia, Uberlândia, v, 13, n. 26, p. 87 - 97.

LEITE, M.E.; BRITO, J.X. S. (2011). Sensoriamento remoto aplicado ao mapeamento do uso do solo urbano e de assentamentos ilegais em Montes Claros-MG. Geosul, Florianópolis, v. 26, n. 52, p. 99128.

MARTINS, G. A. (2010). Estatística geral e plicada. São Paulo: Atlas.

MONTEIRO, C.. A. F. (1992). A interação homem-natureza no futuro da cidade. Geosul, Florianópolis, v. 14, p. 07-48.

MONTEIRO, C. A. de F.; MENDONÇA, F. (2003). Clima Urbano. São Paulo: Contexto.

MOREIRA, A.A; FERNANDES, F.H.S; NERY, C.V.M. (2014). Mapeamento e análise do uso e ocupação do solo na bacia do Rio Vieira no município de Montes Claros/MG. Revista Brasileira de Geomática, Curitiba, v. 2, n. 2, p. 40-48.

MS, MINISTÉRIO DA SAÚDE. Secretaria de Vigilância em Saúde. Departamento de Vigilância das Doenças Transmissíveis. Levantamento Rápido de Índices para Aedes Aegypti (LIRAa) para vigilância entomológica do Aedes aegypti no Brasil: metodologia para avaliação dos índices de Breteau e Predial e tipo de recipientes. Brasília: Ministério da Saúde, 2013. Disponível em: < http://bvsms.saude.gov.br/bvs/publicacoes/manual_liraa_2013.pdf>. Acesso: Janeiro de 2018.

RIZZI, C. B; RIZZI, R. L; PRAMIU, P. V; HOFFMANN, E.; CODEÇO, C. T. (2017). Considerações sobre a dengue e variáveis de importância à infestação por Aedes aegypti. Hygeia, Uberlândia, v. 13, n. 24, p. 24-40.

SEPLAN, SECRETARIA MUNICIPAL DE PLANEJAMENTO E COORDENAÇÃO. Mapa Perímetro Bairros (2009). Disponível em: < http://www.montesclaros.mg.gov.br/infraestrutura/mapas.htm>. Acesso em: 06 de março de 2018.

SMS, SECRETARIA MUNICIPAL DE SAÚDE DE MONTES CLAROS. Número de Infectados por dengue nos bairros da cidade, 2015-2017. Visita ocorrida em: 21 de outubro de 2019.

SILVA, A. M; SILVA, R. M; ALMEIDA, C. A. P.; CHAVES, J. J. S. (2015). Modelagem Geoestatística dos casos de dengue e da variação termopluviométrica em João Pessoa, Brasil. Sociedade \& Natureza, Uberlândia, v, 27, n. 1, p. 157-169.

TEIXEIRA, T.R.A; CRUZ, O.G. (2011). Spatial modeling of dengue and socio-environmental indicators in the city of Rio de Janeiro, Brazil. Caderno de Saúde Pública, Rio de Janeiro, v. 27, n. 3, p. 591-602.

USGS, UNITED STATES GEOLOGICAL SURVEY. EarthExplorer. Disponível em: <https://earthexplorer.usgs.gov/>. Acesso em: 10 de dezembro de 2019.

USGS, UNITED STATES GEOLOGICAL SURVEY. Using the USGS Landsat Level-1 Data Product. Disponível em: <https://landsat.usgs.gov/using-usgs-landsat-8-product>. Acesso em: 03 de abril de 2018. 
UTSUMI, A.G; GALO, M.L.B.T; TACHIBANA, V.M. (2015). Mapeamento de cianobactérias por meio da fluorescência da ficocianina e de análise geoestatística. Revista Brasileira de Engenharia Agrícola e Ambiental, Campina Grande, v.19, n.3, p. 273279. 